\title{
Como é que é 'ver através' uma fotografia?
}

\author{
How is 'seeing through' a photograph?
}

\section{Qu'est-ce que ça fait de «voir à travers» une photo?}

\section{Fernão Pessoa Ramos}

Professor Titular do Departamento de Cinema do Instituto de Artes da UNICAMP (Universidade Estadual de Campinas) e pesquisador CNPQ

Submetido em 30 de Agosto de 2020 Aceito em 29 de Outubro de 2020

\section{RESUMO}

A exposição do argumento de que as fotografias são transparentes, por Kendall Walton, está longe de ser simplória e envolve carga conceitual sofisticada, dentro do campo analítico-cognitivo. Mas podemos ir além disto. 0 fato da imagemcâmera fotográfica de ser transparente, conforme exposto por Kendall, não implica consequência sobre matéria do mundo ser manipulada, alterada ou fatiada. A transparência apenas indica que é 'vendo através' que percebemos o que nos é indicado. É deste patamar que emerge o campo da subjetividade que abriga o que chega de lá, pela transparência. É coisa própria do mundo, ser-aí que habitamos em nossa intuição ou percepção, ao interagirmos com outras coisas e seres. A conformação imagética da imagem-câmera interage sobre a radical indeterminação da presença na tomada, conforme ela transcorre grudada no fluxo da duração. A encenação na tomada, sua mise-em-scène, é um modo de 'morar' na indeterminação radical do acontecer que nos habita como existência. Ela, encenação, potencializa assim a exterioridade num 'de-fora', num aderir ao mundo que, neste modo, a conformação maquínica fotográfica/audiovisual inaugura. Encontra-se nesta imagem, uma espécie de recuo de mim no estar-aí do ser.

PALAVRAS-CHAVE: Teoria da Fotografia; Imagem-Câmera; Tomada;
Transparência; Cognitivismo. 


\section{ABSTRACT}

Kendall Walton's presentation of the argument for the transparency of photography is far from simplistic and involves sophisticated conceptual standards at the analytical-cognitivist thought. But we can go beyond it. This characteristic of camera images to be transparent does not imply that the world cannot be manipulated, altered, or sliced. Transparency only indicates that it is 'seeing through' that we perceive what is indicated to us. And, what appears, is a 'beingthere' where we inhabit, interacting with things and beings. Camera-image's conformation interacts with the radical indeterminacy at the openness of presence in the take. Through staging, or mise-en-scène, we manage to 'see through' exteriority in the automatic machinic camera conformation, as it joins us in the way we recognize as ours. We can consider it as a kind of retreat, from 'me', in the being-there of the world.

\section{KEYWORDS: Photography Theory; Camera-Images; Take; Transparency;} Cognitivism.

\section{RÉSUMÉ}

La présentation par Kendall Walton de l'argument de la transparence des photographies est loin d'être simpliste et implique un chargement conceptuel sophistiqué dans la pensée analytique et cognitive. Mais on peut aller au-delà. La caractéristique de l'image-caméra d'être transparente n'implique pas, bien entendu, que la matière du monde ne puisse pas être manipulée, modifiée ou tranchée. La transparence indique seulement que c'est en 'voyant à travers' que nous percevons ce qui nous est indiqué. C'est à ce niveau qu'émerge le champ de la subjectivité qui recouvre ou abrite ce qui vient à nous, comme quelque chose de propre au monde, dans un 'être-là que nous habite comme intuition, ou dans notre perception. La conformation imagetique de l'image-caméra', dans sa façon d'interagir sur l'indétermination radicale du présent, se déroule collée au flux de la durée. Par la mise en scène, elle parvient à exposer l'extériorité de la conformation machinique en tant que peau du monde. On se trouve, alors, comme dans une sorte de retraite du moi dans l'être-là.

MOTS-CLÉS: Théorie de la Photographie, Prise de Vue, Image-Caméra, Cognitivisme, Transparence.

Dossiê Crise, Feminismo e Comunicação - https://revistaecopos.eco.ufrj.br/

ISSN 2175-8689 - v. 23, n. 3, 2020

DOI: $10.29146 /$ eco-pos.v23i3.27615 
É bem conhecido que, por décadas, nós vivemos em uma oposição artificial entre a filosofia anglo-americana, que supostamente seria racionalista, baseada na análise formal da língua e da lógica matemática, e a filosofia continental, supostamente à beira do irracionalismo, baseada numa sensibilidade literária e poética da expressão.

(Alain Badiou, prefácio a "O Ser e o Evento")

Ser e, por conseguinte, também os modos de ser - ser-possível, ser-atual, ser-necessário - não exprimem o que é o objeto, mas o como da relação do objeto com o sujeito. (Martin Heidegger, "A Tese de Kant sobre o Ser")

I

Algumas das formulações, mais caras à teoria recente, afirmam que a imagem de origem fotográfica, a imagem-câmera, não é transparente ao mostrar o mundo. Por esse caminho, em sendas diversas, colocam-se autores como Philippe Dubois (1993), Arlindo Machado (1984), Vilém Flusser (2013) de um lado - com ênfase mais desconfiada na tecnologia da câmera quando encontra o mundo - ou Susan Sontag (2004), Roland Barthes (1984), com uma abertura maior para a metafísica, ou a "aura", do encontro com o outro. No primeiro grupo, a posição dominante vem do pensamento que analisa o maquinismo como uma espécie de "caixa preta" (conceito caro a Flusser) sub-reptícia, "aparelho operador" que codifica disfarçado enquanto opera. Trata-se de uma teoria desconfiada com a tecnologia e as "imagens técnicas", resultando posteriormente numa posição mais ou menos negativa face à sociedade de massas, a modernidade e a conformação de seus produtos pela indústria cultural. Em seu coração reside uma visão que remonta ao início da primeira metade do século XX e demonstra choque ao encontrar uma nova dimensão tecnológica presente no cotidiano de uma sociedade recém-urbanizada. Choque que se estende, em outros horizontes, do existencialismo de Martin Heidegger à teoria crítica de Frankfurt em seus primórdios, passando por Walter Benjamin. O segundo grupo parte, como o 
primeiro, da análise estrutural que tem raízes metodológicas nos avanços da linguística no século XX, mas, a partir da década de 1970, faz a curva em direção a regiões menos áridas. Encontra a psicanálise e enverga num tête-à-tête com questões que envolvem a representação e seu sujeito, agora flexionados pelo tempo e pela duração.

Pensar a opacidade da imagem fotográfica carrega consigo o conceito de ideologia para a desconstrução, mas o faz (quando em seu formato mais simplório) de maneira que o projeto desconstrutivo entale na superfície exterior da linguagem, ou da representação, sem cumprir sua missão maior: a da radicalidade da fundação de uma nova subjetividade (ou do que restou dela) na différance, no sentido que Derrida (1994) a estabelece. A visão mais rala da opacidade a denuncia como um império maligno, aquele da subjetividade cooptada por forças que lhe são estranhas. Na realidade, é neste ocultamento que deveria mergulhar, sem buscar sair impune do outro lado. Inerente à subjetividade reificada, estaria a dimensão chamada de 'ideológica' da enunciação. 'Ideológico' muitas vezes é tomado como conceitual de origem marxista, referindo-se a um sistema de ideias que se vincula à reificação da consciência do valor, num modo de produção em que o trabalho é incorporado como mercadoria, mas figurado como fetiche. Trata-se de mostrar intervalo no entendimento do social e do humano que se articula em sistema de ideias vinculadas, em sua representação, pelo mecanismo tecnológico que dá opacidade às relações sociais sustentando o modo de produção promovido pelo regime capitalista na troca de mercadorias. A opacidade traiçoeira, como dimensão ideológica que funciona graças ao dispositivo tecnológico (seja aquele da representação maquínica, seja o envolvido na reprodução fabril da mercadoria), é necessária para a realização do valor do trabalho e a própria reprodução do capital, no centro do sistema econômico.

A ideia da impossibilidade da representação que transparece o mundo pela imagem-câmera e o seu maquinismo, está, portanto, vinculada à visão de uma 
sociedade com forças sociais reificadas pelo fetichismo da mercadoria. Neste sentido, para caber na visão dominante na contemporaneidade, a teoria da imagem afirma que a imagem-câmera fotográfica, ou em movimento, apesar de sua forma perspectiva especular, não reflete a realidade, mas traz a imagem desta realidade já construída, desde seu maquinismo conformador como dispositivo que, historicamente, é "burguês", contemporâneo à ascensão da burguesia como classe (Comolli, 1971-1972). É o que quer nos demonstrar certa teoria do cinema e da imagem dos anos 1960, na qual repousam autores mais contemporâneos como Dubois ou Machado, ao menos em suas formulações primeiras.

0 mecanismo representacional da câmera e seus dispositivos seriam opacos, e também burgueses, pois a forma especular perspectiva é gerada, historicamente, dentro do contexto de ascensão do modo de produção capitalista que serve à sua classe social dominante, a burguesia. Corresponderia a demandas ideológicas de um momento histórico específico que requer a naturalização (enquanto ocultamento) das relações sociais. Na teoria do cinema, o conceito central para trabalharmos este deslocamento é o de "sutura" (Oudart, 1969) que, de origem psicanalítica, surge simultaneamente junto ao de "dispositivo", compondo o quadro dominante na análise da imagem-câmera no final da década de 1960. Dispositivo é um conceito chave para trabalharmos com a imagem técnica. Possui uma densidade que foge aos horizontes deste artigo, tanto nas primeiras formulações de Michel Foucault, como em Gilles Deleuze em seus últimos escritos, assim como em Giorgio Agamben em sua síntese posterior (Agamben, 2005).

No caso da fotografia, a referência mais comum que encontramos nos manuais é relativa ao paralelismo de sua afirmação histórica com a arte renascentista. Seu estilo, baseado na construção perspectiva, ocultaria o ponto de vista de afirmação da subjetividade, a partir do qual emana o sujeito da representação. A imagem perspectiva especular da câmera reproduziria, na 
naturalização da construção pelo dispositivo maquínico, o contexto em qual, na ação apropriadora da classe burguesa, o sujeito oculto detentor do capital é reificado para valorar o trabalho como fetiche. A análise pioneira de Foucault em "As Palavras e as Coisas" (Foucault, 2000), abordando o trabalho pictórico de Velasquez em "As Meninas", exerce aqui grande influência. Ela serve de inspiração para a visão do dispositivo oculto como motor da reificação embora, nos manuais, nem sempre venha acompanhada das mediações que envolvem o pensamento original foucaultiano e que certamente vão além da elegia mais simplista da desconstrução reflexiva e da denúncia do fetiche da perspectiva.

Há um terceiro grupo que trabalha este tema e é pouco conhecido no Brasil: os dos pensadores anglo-saxões, basicamente americanos e ingleses, que utilizam conceitual da filosofia analítica e do cognistivismo para pensar a fotografia e a imagem-câmera. Em "Transparent Pictures: on the nature of photographic realism", Kendall Walton discute de modo explicitamente polêmico a questão da transparência das imagens-câmera, afirmando que a imagem fotográfica é transparente (Walton, 1984). Segundo o autor, podemos, literalmente, "ver através" destas imagens e olhar o mundo em sua dimensão como objetividade exterior, coisa puramente objetiva, como o vemos através de binóculos, lunetas ou microscópios. Para ele, vemos o mundo que nos é exterior com nossos próprios olhos, como entidade fenomênica, assim como o vemos através de fotos, ou de próteses oculares diversas. Ele, mundo, chega a nós como produto de uma mente que o realiza em nossa natureza interior, perceptiva ou imaginativa, pela mediação sensorial - mas, como coisa ou ser de objetividade exterior. 0 mundo que chega a nós através de uma foto (analógica ou digital, tanto faz) possui a mesma dimensão empírica que ele tem quando bate, flexiona, comuta em nossos sentidos através próteses oculares. E assim possui a dimensão de singularidade desta comutação que está ausente em nossa imaginação nas representações pictóricas. 
A exposição do argumento da transparência das fotografias por Kendall Walton está longe de ser simplória e envolve carga conceitual sofisticada. Transita com agilidade por áreas próximas ao campo analítico e à psicologia cognitivista, mas com abertura para a tradição filosófica que os insulares ingleses gostam de chamar de "continental". Seu ponto de vista é que imagens fotográficas (e ele amplia em diversos momentos a análise para a imagem que se move mediada por câmera, seja no filme, seja na televisão ao vivo) sustentam e provocam uma forma de visão similar à forma de visão que empregamos ao olharmos o mundo através de telescópios, microscópios, periscópios, binóculos, espelhos. Não se trata de reduzir a fotografia à imagem especular, ou reduzir a câmera à um aparelho mecânico auxiliar da visão. Walton reconhece o estatuto representacional da fotografia e a densidade subjetiva na criação artística que o aparelho câmera pode eventualmente proporcionar. No entanto, pensa esta dimensão representacional com estatuto 'objetivo', como uma nova "forma de visão" que a imagem-câmera produz pelo espectador. Esta nova visão é baseada na capacidade da fotografia em permitir ao espectador "ver através" da tessitura da imagem, em direção posicional direta ao mundo que a conformou, ainda que tenha de fissurá-lo, quebrando a unidade que emerge fundada no existir. Neste caso, é inevitável respirarmos a metafísica temporal do "punctum" barthesiano, mas que Walton vai tergiversar na aridez própria ao pensamento analítico. Trata-se de uma questão que surge presente nas abordagens analíticas mais instigantes e costumam deixar a sensação de cobertor curto. É difícil levarmos até a última consequência a lógica fria, com marcha reduzida, da consecução nas deduções - e fazer nelas entrar a duração e seu fluxo.

Para Kendall Walton, olhamos através das fotos do mesmo modo que olhamos através de lentes macroscópicas e vemos as crateras da lua; ou olhamos através de lentes microscópicas e vemos os pelos das pernas de um ácaro; ou olhamos através do espelho angular e vemos o carro que se aproxima além da 
esquina e em função desta objetividade reagimos. É deste mesmo modo que olhamos para o "mostrar-se", para a "posição", que vem do mundo para nós nas fotos. 0 que vem de fora, e vem através da câmera e sua imagem fotográfica, de algum modo bate em nós como o mundo que transcorre, lá, no espaço distante onde jamais corpo humano ocupou (o planeta Terra visto de Marte, por exemplo). Ou ainda, chega do passado, quando vemos "através" do nosso avô Samuel antes que tivéssemos nascido (exemplo caro à Roland Barthes, na fotografia do jardim de inverno de sua mãe), ou através da foto vemos agora Napoleão III, que existe como ente que então existiu pela presença de seu corpo face a cena que o daguerreótipo abriu no mundo. Sabemos, apenas, que já vimos (de alguma maneira, no modo que o maquinismo da câmera fica no universo), como é a Terra vista de Marte - mas não vimos ainda (pois não há imagens-câmera) como a Terra, ou o Sol, são vistos de fora do sistema solar (da estrela mais próxima, por exemplo). Não vimos, pois ainda não pudemos olhar "através", para nosso mundo e para nós, a partir desta presença maquínica que a câmera consegue "presentear" no modo de uma presença, que esboça fundar em nossa ausência - circunstância da tomada da qual compartilhamos, como um estar aí na existência.

"Ver através" de uma imagem-câmera a Terra vista de Marte, equivale a ver através nossos olhos (ou por prótese ocular) a Terra de Marte? Ontologicamente não sabemos pois, por assim dizer, ninguém ainda esteve lá para conferir. Saberemos como será vista a Terra vista de Marte quando um corpo humano estiver lá, olhar a Terra e falar de sua sensação sobre a matéria Terra atingindo diretamente o sentido da visão em seu corpo. Sabemos hoje apenas o que o nosso corpo verá como imagem-câmera em Marte (pele do mundo apanhada maquinicamente como imagem reflexa da circunstância da tomada), a partir da conformação de sua figura pela analogia entre a forma reflexa da imagem-câmera e as formas reflexas naturais que nos cercam no mundo. Sabemos apenas, pelo meio do maquinismo câmera, de sua semelhança (de onde nosso espanto quando se fixa

Dossiê Crise, Feminismo e Comunicação - https://revistaecopos.eco.ufrj.br/

ISSN 2175-8689 - v. 23, n. 3, 2020

DOI: 10.29146/eco-pos.v23i3.27615 
e se descola pela decalagem temporal) às representações reflexas que pipocam a extensão do mundo em superfícies planas. Estas são bem conhecidas nossas, desde a origem da humanidade, e é por elas que o cogito separa-se na imaginação de si: "vejo, e imagino, que ele sou eu na poça de água em que me vejo refletido... então existo nesta poça e em mim para poder ver-me assim". Isto é, ao final, "ver através" uma fotografia, como vemos o mundo através da figura que fica na poça enquanto estou lá e como sabemos o que é "ver" a Terra de Marte. Visão do espaço sideral que traz um estatuto todo particular, pois a aproxima da experiência do mundo sensível mais próximo, quando tocado por nossa imaginação.

\section{II}

Para nossa visão, para a consciência desta visão, a imagem-câmera traz o mundo como objetividade, numa totalidade que abarca nossa particularidade. A universalidade plena em si-mesma é como um estar-aí (do qual a experiência é maquínica) que se descola por dentro. Surge numa interação causal com o maquinismo da câmera, que incorporamos à experiência sensível que é própria do que se constitui em exterioridade a nós. Neste sentido, contanto haja a "tomada" propriamente na origem, contanto haja contato com a coisa exterior, a questão do suporte no maquinismo câmera não se coloca como essencial. 0 debate, que muito tempo nos preocupou, sobre as diferenças, supostamente radicais, entre o suporte analógico ou digital, encontra-se hoje defasado. Praticamente a totalidade das imagens fotográficas (ou audiovisuais) das imagens-câmeras é hoje digital e o modo pela qual adquirem significado se alterou pouco.

O diferencial situa-se no campo de sua distribuição midiática, pelas redes sociais, hoje qualitativamente distinta em sua velocidade e abrangência. A particularidade, do universo digital das imagens, não é a pequena decalagem do grau de manipulação existente entre os suportes digitais ou analógicos, ou uma

Dossiê Crise, Feminismo e Comunicação - https://revistaecopos.eco.ufri.br/

ISSN 2175-8689 - v. 23, n. 3, 2020

DOI: 10.29146/eco-pos.v23i3.27615 
suposta relação ontológica do suporte analógico versus a composição mais marcada, algorítmica e binária, da imagem digital. A visão desta distinção como algo radical correspondeu ao momento de chegada da nova imagem digital. Hoje, percebemos que existe similitude e identidade no modo pelo qual "vemos" e experimentamos, com afeto empático, imagens digitais ou analógicas desde que mediadas por câmera. É assim que nos recordamos como experiência própria, com empatia através da imagem-câmera digital, da praia em que estivemos em nossas últimas férias de verão; ou experimentamos surpresa, ou indignação com as imagens analógicas (película) do assassinato de John Kennedy em novembro de 1963; ou as imagens em suporte vídeo do espancamento de Rodney King em novembro de 1991; ou ainda as imagens digitais do cruel assassinato de George Floyd em maio de 2020. O diferencial não está no suporte (fotográfico/ "analógico", eletrônico/ "videográfico", ou digital/ "algoritmo"), mas no fato de sabermos que a imagem que vemos é uma imagem-câmera e, como tal, é derivada do funcionamento do maquinismo câmera sustentado por um "sujeito-da-câmera" na circunstância de presença a que chamamos "tomada". A tomada possui seu modo singular de interagir com a circunstância do mundo que transcorre constituindo a cena que vemos "através" da imagem-câmera fotográfica/audiovisual.

É assim que ela, imagem-câmera, chega a nós, através das particularidades de nossa percepção, quando a encontramos como fenômeno no mundo, ou quando a entretemos na imaginação da representação imagética que vemos. Esta é a modalidade diferencial da imagem fotográfica inaugurada no século XIX e que nos atravessa por todos os poros agora no século XXI. Traz o mundo fechado em si pela tomada em sua exterioridade e, neste sentido, difere da imagem pictórica. Quando olhamos através de uma pintura não vemos nada "através", mas a densidade opaca da expressão estética de outrem, o pintor.

Dossiê Crise, Feminismo e Comunicação - https://revistaecopos.eco.ufrj.br/ 
Encontro, então, a sensibilidade estética da singularidade do artista em sua expressão. Olhar a fotografia nos traz o mundo "de-fora", como uma torre que, emergindo, pipoca ou estoura por si mesma na extensão da planície do presente, amarrada previamente na totalidade de suas partes. 0 sujeito-da-câmera é uma mônada e o "amarramento" em seu todo unitário compõe-se em extensão pela subjetividade, emergindo em bloco instantâneo que traz a totalidade em cada representação particular (no limite de sua diluição na totalidade), em cada pontocâmera (como o mundo também pipoca, súbito, em reflexo na água quando para ela olhamos, ou não). Traz assim o modo em que se abre, ou se abriu, no mundo como estar-aí no qual habito e que foi tomado através do sujeito-da-câmera corpo maquínico de coisa exterior, que assim trouxe algo na experiência de minha carne. Ainda na fotografia mais abstrata, aquela em que as coisas do mundo desaparecem e a circunstância da tomada se esvaece, a comunhão com o mundo, pelo estar-aí, deixa seu traço (no cristal de prata preparado, ou no algoritmo pensado para impressionar o mundo na câmera).

Certamente existem imagens digitais internas, imagens tecnológicas, totalmente elaboradas por computador, obtidas sem o meio da tomada. Também antes do digital, o trabalho de animação podia ser baseado na sucessão de imagens pictóricas maquínicas sem tomada. Mas não são estas as imagens que tratamos neste artigo. Aqui buscamos pensar como é que vemos através das fotografias e o que encontramos lá, como mundo que vem de fora - ao nos depararmos com o maquinismo que "toma" este mundo e o traz por nós em "tomada".

\section{III}

A característica da imagem-câmera de ser transparente não implica, por certo, que a matéria de seu mundo não possa ser manipulada, alterada ou fatiada. Mas a transparência apenas indica que é "vendo através" que percebemos o que

Dossiê Crise, Feminismo e Comunicação - https://revistaecopos.eco.ufri.br/

ISSN 2175-8689 - v. 23, n. 3, 2020

DOI: 10.29146/eco-pos.v23i3.27615 
nos é indicado. É deste patamar que emerge o campo da subjetividade que cobre ou abriga o que chega de lá, coisa própria do mundo, do ser-aí que habitamos em nossa intuição ou na percepção interagindo com coisas e seres. Imagens especulares podem ser alteradas, ou serem disformes, no sentido côncavo ou convexo, por exemplo, conformando uma relação de objetividade com a exterioridade no reflexo, pela proporcionalidade entre as partes de sua figura e a coisa exterior. Esta deformação não impede que a coisa exterior seja vista em sua presença por nós, no modo em que atinge nossa percepção, através do espelho. Nada impede que através de um espelho, convexo ou côncavo, em nossa parede, possamos nos assustar ao vermos um intruso entrar em nosso quarto. E que a fotografia em grande angular, mesmo deformando o mundo que representa, seja prova do crime que se quer mostrar. E que a pintura do mesmo crime não mostre nada que incrimine pelo que representa, a não ser o testemunho da livre imaginação do artista plástico que viu o crime e, assim que o assistiu, desenhou.

Como não nos faz ver "através", a imagem pictórica não possui, socialmente, o peso judicial que as imagens-câmera, imagens resultantes do maquinismo câmera na tomada, possuem e que as permitem servir de prova. Prova certamente aberta à interpretação e eventualmente à manipulação, mas que traz seu fundamento diferencial na "mundanidade" compartilhada do "ver através", que nos permite perceber, por nossos sentidos, o que esteve "fora" e lá (quando) se constituiu. Objetivação da totalidade da extensão no modo de um automatismo que está ausente na representação pictórica de um desenho sem "tomada", por mais próximo que este desenho consiga ser da forma especular-perspectiva.

A visão direta do mundo, sem mediação da figura imagética, também é traiçoeira, como constantemente constamos em nosso cotidiano ao abrir espaço para o que denominamos "interpretação". Por que seria então diferente com a fotografia? Ser transparente não significa ser neutro ou verdadeiro. Significa possuir o estatuto de compartilhamento da exterioridade, não em absoluta 
objetividade, mas como presença do outro (ou de outrem) em minha existência. A sobreposição entre objetividade e verdade resta aberta em seu viés hermenêutico, inclusive para a teoria que se cerca de enunciados com preocupações lógicoanalíticas, conforme expusemos. Como afirma Walton, "ser transparente não significa necessariamente ser 'invisível'” (Walton, 1984, p. 252).

"Nós podemos nos enganar quando vemos coisas diretamente. Se câmeras podem mentir, também podem nossos olhos. Ver uma coisa através de um espelho distorcido significa assim mesmo vê-la, ainda que nos enganemos a seu respeito" (Walton, 1984, p. 258). A questão do estatuto da tecnologia é central para entendermos o maquinismo-câmera, mas sua sobre-determinação pode resultar nas armadilhas que encontramos em trabalhos como os de Flusser ou Machado. A desconstrução do maquinismo não deve se reter num desvendamento evidente, mas ir além. Aí talvez se depare realmente com o que automatismo revela em seu encontro. Nele, a representação maquínica não se constitui propriamente, mas eclode nossos sentidos, na coincidência da maneira pela qual nosso ser está lançado no mundo. Trata-se da experiência do que é a existência no modo de uma tomada. Antes de buscar-se a revelação pragmática da "caixa preta", no sentido do "desvendar" mais raso de uma tecnologia oculta, caberia arriscar uma fenomenologia da própria experiência. É escuridão que não se desvela pelo que sabemos ou negamos em nosso entendimento, mas pelo que nela vemos ao a encararmos, existência como mundo que traz aquilo que nos habita. É horizonte de um abismo vazio no qual mergulhamos ao querer olhar o fundo, mas que neste infinito possui a profundidade da superfície da facticidade.

A imagem-câmera, fixa ou em movimento, com suas particularidades, mostra, então, neste modo diferencial, sua composição como imagem em figura do que não a determina propriamente em fechamento. Estamos analisando como esta constitui-se em modalidade plena, a partir do século XIX, através da fotografia. Datam daí as primeiras imagens-câmeras retendo, indefinidamente, o ser-aí do 
mundo que existe pela minha comunhão no modo da tomada, particularidade da configuração representacional, espécie de para-si enquanto totalidade universal que se imiscui. 0 caráter independente, exterior, do que bate e se plasma com forma reflexa no suporte, tem este caráter de ser do mundo existindo em sua cotidianidade, em sua banalidade, retido na manifestação da circunstância em tomada e fixada por um maquinismo (a câmera). É ela, câmera, que se impõe como um si-mesmo (o sujeito-da-câmera), como casca do exterior (pois não é propriamente uma sensação), na subjetividade que o representa. É uma adição (nas manipulações da fôrma imagem-câmera) que pode ser colada como pele ao que lhe origina. Este suplemento traz algo que vem de fora, que está fora como ser, e é no modo que atinge nossos sentidos que aparece. Assim, promove pela imaginação sua percepção e nossa consciência/memória do mundo.

A manifestação da exterioridade do mundo pela conformação maquínica que o retém, não significa negação de uma "autoria". Não significa a possibilidade do sujeito se debruçar sobre este mundo flexionando-o, nem a negação da intencionalidade e sua dimensão ideológica. A pele do mundo pode nos enganar, ludibriar, mas nosso uso dela como fotografia não é intrínseco ao engano. Também o intervalo para sua manipulação pelo juízo estético é imenso. Significa que, na conformação fotográfica (aquela da imagem-câmera em seus diversos suportes), o artista lida com um mundo que se articula na comutação consigo num "de-fora". Mundo que, por estar-aí, se apresenta ao modo maquínico especular como uma morada que habita o ser, ultrapassando, pela forma dura, amarrada em totalidade em-si, o obrar estético da subjetividade que repousa na própria imaginação. A fotografia é uma espécie de resto do que bateu nela, sensação. Neste ricochetear pode produzir aquele efeito de estranheza que o si-mesmo possui ao encontrar-se com um para-si antes absoluto, mas que agora abre-se no abismo de uma clareira que ultrapassa ele próprio, o sujeito.

Dossiê Crise, Feminismo e Comunicação - https://revistaecopos.eco.ufrj.br/ 


\section{IV}

É esta a matéria dura e fechada do mundo que o sujeito-da-câmera fotógrafo encontra quando se expõe ao maquinismo fundando a cena. Para tal, para sua arte, ela precisa ser vivida, ser cuidada, ser partilhada como experiência, e é isso que ele faz ao existir na circunstância da tomada. Lá está a coisa e o outro simesmo que ele atinge, no modo da intersubjetividade compartilhada pelo meio do maquinismo câmera. A isto, a este tipo de existência que é a de habitar o mundo pela tecnologia do maquinismo, chamamos de cena, ou de encenação na tomada ou ainda "mise-en-scène", quando se realiza embebida na tradição da arte fílmica. 0 plasmar do mundo na imagem-câmera pelo sujeito-da-câmera, para o espectador, comuta-se na intenção e conforma-se na imaginação num modo originalmente distinto das imagens pictóricas ou esculturais não maquínicas - embora formas mistas entre elas sejam certamente possíveis e tenham grande potencial estético.

No sentido da peculiaridade, muitas vezes a conformação imagética da imagem-câmera-em-movimento interage sobre a radical indeterminação do mundo presente, transcorrendo grudada no fluxo da duração. Pela encenação, consegue dobrar-se na indeterminação da presença, afirmando sua liberdade sobre a exterioridade do maquinismo em seu modo de aderir ao mundo. A composição fílmica do mundo que emerge neste tipo de encenação é chamada de "cinema direto" ou "verdade", em seu estatuto de mise-en-scène documentária. Neste caso, o modo de interação intersubjetiva da cena fílmica, que varia em função de ser mais recuada ou interativa (no modo reflexivo/verdade), compõe a dimensão propriamente estética da arte fílmica documentária, aqui caracterizada pelo recuo radical que avança até a práxis interveniente. Nesta articulação, o ser-aí que habita a indeterminação é assim levado pela mão como sujeito-da-câmera na encenação, liberto na potencialidade de seu próprio transcorrer, no modo em que se encontra conosco no mundo.

\section{Dossiê Crise, Feminismo e Comunicação - https://revistaecopos.eco.ufri.br/}


A encenação fílmica carrega consigo diferentes maneiras de asserir (chamamos também "vozes": em "over", ou encorpadas em diálogos) que dão forma à narrativa quando ela se fecha (ou abre-se) pela transformação da tomada em plano na articulação propriamente fílmica da montagem ou edição. A narrativa fílmica, propriamente, tem uma instância, a do megaenunciador, que lida com isto. O mundo na imagem-câmera traz a extensão como eclosão na unidade especular e o sujeito pode triturá-la, enfrentá-la na tomada, como a "coisa" da mundanidade. Pode também compartilhá-la na cena, dispondo-as (tomadas) no modo dos planos. O plano configura a tomada que transcorre na unidade maior que o sobrevoa e o agarra em multiplicidade, articulando-o na junção fílmica para a voz do megaenunciador. 0 filme passa, mas certamente não passa na medida do suporte da câmera, pele da duração (a não ser naquela arte que tende ao pasoliano "plano sequência infinito", ou no "cinema direto" total). 0 suporte do filme que passa (hoje digital, antes película), por sua vez, sempre "corre", ou passa, ou dura, em simultaneidade com a duração indeterminada, aberta, do mundo.

O suporte corre de modo preciso na câmera em seu tempo cronológico, como a tartaruga e Aquiles no paradoxo de Zenão. Mas com as posições invertidas da aporia, que se enrosca no tempo quando o coloca fora da duração, fora da qualidade absoluta do "kairós". Ele, Aquiles, nunca ultrapassa tartaruga, e ela ganha a corrida - mas, no nosso caso, a tartaruga que passa na tomada perde, porque, pela arte, a corrida não fica aí na medida do suporte que transcorre. No entanto, é sempre daí, da aderência cronológica ao presente, de seu paradoxo, que se parte para aventura. Isto parece esquecer certa reflexão contemporânea mais afoita em levantar o voo. É pela figuração da coisa fílmica que, diferencialmente, o intervalo pode evaporar e a corrida da cronologia infinita ser ganha na expressão daquilo que nunca se fecha, fazendo presença do que ultrapassa quando futuro e passado colam.

Dossiê Crise, Feminismo e Comunicação - https://revistaecopos.eco.ufrj.br/

ISSN 2175-8689 - v. 23, n. 3, 2020

DOI: 10.29146/eco-pos.v23i3.27615 
0 fato é que as imagens-câmera, por serem transparentes, derivam sua origem dum mecanismo automático e tecnológico. Se a imagem especular num lago é automática, a imagem-câmera também é automática, mas, diferença essencial, é tecnológica. Envolve um tipo de compartilhamento com o mundo que decorre da técnica, maneira particular que tem o trabalho de transcender a coisa. É mecanismo tecnológico construído para captar, em suporte, o traço da causalidade que a matéria física imprime, seja no modo digital, ou no analógico. É assim que este 'de-fora' se confronta como imagem no suporte: pelos "cristais de prata" da emulsão, ou pelo algoritmo digital que pelo mecanismo corre ou passa.

Trata-se de dimensão que tem sua expressão numa fenomenologia de sua referencialidade, no sentido que pode possuir o belo conceito da "primeiridade" na tríade perceiana: qualidade, semelhança, ou ainda o que Peirce chama de "ground" - em seu poder designativo absoluto, ou primário, ancorado na sensação da matéria. É como se expressa a categoria do qualisigno, às vezes trabalhada mais estreitamente pela semiótica focada no realçar da camada de mediação, própria à toda representação. A comunhão no habitar do mundo pela expressão da qualidade, traz, portanto, nesta forma imagética específica da circunstância fechada (a tomada), em seu modo comunicacional, a especificidade que estamos tentando definir. Neste momento, ela se determina pela transparência da qualidade, ícone que adere como pele, em sua "primeiridade" de "ground" (eclosão absoluta da qualidade icônica), trazida em sua interatividade como matéria do traço, fator da força bruta, posição, ação, do ícone no signo (secundidade) que ao se constelar o faz sobre aquele que a recebe no modo espectatorial.

Encontramos assim a singularidade desta imagem radicalmente nova na cultura humana, neste âmago que é sua constituição no mundo, na diversidade da exploração estética que sobre ela se abre. Funda, em seu aparecimento histórico, uma nova dimensão da imaginação no "ver imagens", aquela que se caracteriza pelo "ver através", inaugurando a possibilidade de um "lançamento" 
fenomenológico do olhar num recuo que quer tender ao absoluto, mas sempre habita o que se separa. Assim, a experiência se desfaz, espectadora do mundo na circunstância de sua existência na tomada, para lá, e de lá mesmo, se lançar, buscando constituir-se num encontro que é nele a extrema fronteira de sua dimensão como figura.

\section{V}

O trabalho de Kendall Walton, embebido na sintaxe e na lógica do conceitual analítico, tem o mérito de distanciar-se de abordagens mais cruas. Walton afirma que:

"parte do que é ver alguma coisa, significa ter experiências visuais causadas de um modo puramente mecânico. Objetos causam mecanicamente suas fotografias e as experiências visuais dos espectadores, o que nos permite ver os objetos através das fotografias. Em contraste, objetos causam pinturas não de forma mecânica, mas de um modo mais 'humano', um modo que envolve o artista. Então, não vemos através das pinturas" (Walton, 1984, p.261).

0 autor realça aqui a singularidade da fotografia no "ver através", frisando sua dimensão na perspectiva conceitual do pensamento analítico-cognitivo, campo no qual também trabalham pensadores como Noël Carroll e Gregory Currie. Estes últimos digerem mal as afirmações de Walton, esboçadas inicialmente em seu livro "Mimesis as Make Believe - on the fondations of the representational arts" (Walton, 1990). 0 "ver através" da fruição espectatorial das imagens com origem fotográfica é, neste livro, desenvolvido pela postura do que chama de "imagining seeing" ('imaginar ver'). Currie é mais próximo de Walton do que Carroll, mas marca um ponto diferencial enfatizando o aspecto (central para certa psicologia cognitivista) que o espectador de uma foto não mantém relação causal, do tipo empirista, com o contexto espacial do mundo que fundamenta a imagem. Como poderíamos "ver 
através" uma fotografia, do mesmo modo que "vemos através" um espelho ou telescópio, se não compartilhamos, enquanto presença, o espaço como objetividade extensa no universo representado? Trata-se, então, entre fotos e próteses oculares, de contextos cognitivos diversos. Se as reservas de Currie tornam-se relativas para a imagem-câmera ao vivo (e o debate entre Carroll, Currie e Walton, irá estabelecer este ponto), a ausência da contextualização espaçotemporal do representado, na atualidade da fruição da fotografia como visão do mundo "através", é central em sua posição.

Currie desenvolve seu argumento de linha cognitivista, acentuando o fato de que ver uma fotografia não nos fornece "informação egocêntrica" ("egocentric information") daquilo que estamos vendo. Para o autor, ver - seja diretamente, seja através de espelhos ou aparelhos oculares - envolve uma série de informações cognitivas espaço-temporais que situam o corpo de quem vê com relação aos objetos e seres que vê. Ver "através de fotografias", neste sentido, diferencia-se de ver "através de lentes e espelhos": "fotografias não transmitem informações egocêntricas; ver uma fotografia não me diz nada sobre onde o objeto fotografado está em relação a mim" (Currie, 1995, p. 66).

Deslocando assim a questão da transparência, que permitiria o espectador "ver através" em Walton, Currie equivale a visão de uma foto a outras situações que envolvem relação entre índices e percepções sensoriais e que não possuem a dimensão icônica ou simbólica, embora sempre frise a dimensão da intencionalidade. 0 maquinismo da fotografia não demanda intenção em seu automatismo mecânico, ao contrário da imagem pictórica, que não traz a camada da eclosão da totalidade reflexa. Ver uma fotografia teria equivalência, neste aspecto, a olhar a marca um termômetro, por exemplo, enquanto índice de indicação de calor. A dilatação do mercúrio como marca do calor, traz a mesma qualidade que a foto possui ao fincar uma dependência causal com seu referente. Mas a fotografia é uma representação e Currie não esquece esse aspecto. A 
equivalência faz diferença e Currie a afirma numa fraca sobreposição entre os campos do "ver o mundo ordinariamente" e o "ver o mundo através de fotografias". "A sobreposição não é maior daquela existente entre os erros característicos que descriminam o 'perceber o calor' e o 'ver termômetros'. Não existe espaço aqui para afirmar que a percepção de uma fotografia seria a percepção de um objeto fotografado" (Currie, 1995, p. 67).

Estamos em pleno exercício dos dilemas próprios à concepção cognitivista do mundo, no modo mais característico de sua derivação sobre a representação e as artes. A equivalência entre perceber o calor (como sensação) e sua medida no termômetro serve de base referencial para estabelecer a relação diferencial entre a percepção do mundo e sua representação por meio do maquinismo câmera. A análise de Currie explora igualmente a distinção entre as próteses oculares na percepção direta espaço-temporal e a retenção do mundo pela fotografia. Para ele, é sobre esta retenção que a visão do espectador se detém, sem a informação espaço-temporal egocêntrica na relação que estabelece com o sujeito-da-câmera que vê na tomada. A imagem seria apenas uma equivalência inicial entre ela e seu referente, equivalência comum ao conjunto de signos (termômetro/calor) que possuem relações causais entre o que expressam e os elementos formadores de sua significação. Sobra a questão de como abordar as consequências da fotografia se constituindo como representação propriamente, elemento que foge às análises de Currie e nos quais a abordagem de Walton está centrada.

Um dos perigos da análise de base cognitiva-analítica, na teoria do cinema documentário ou da fotografia, no recorte que encontramos em Currie, é o de se deixar prender por especificidades psicológicas, ou lógico-dedutivas, que acabam por abandonar a dimensão propriamente estética, o universo da expressão que vem constituir a imagem em sua disposição fotográfica ou fílmica. A expressão de uma "aisthésis", composição carregada por sensações, na qual o conceito de "representação" ainda tem de servir de âncora para obter densidade e levantar voo

Dossiê Crise, Feminismo e Comunicação - https://revistaecopos.eco.ufrj.br/

ISSN 2175-8689 - v. 23, n. 3, 2020

DOI: 10.29146/eco-pos.v23i3.27615 
no campo dos afetos, torna sem sentido análises da causalidade cognitiva na fotografia definidas, por exemplo, no argumento da comparação entre termômetros e imagens. São perigos aos quais se expõe a lógica expositivadedutiva que se baseia o raciocínio analítico, principalmente quando carrega consigo as certezas do cognitivismo.

Noël Carroll enfatiza as restrições de Currie ao conceito de "ver através" de Waltson, mas explora outra perspectiva. Busca uma definição que chama de "ontológica" das imagens em movimento. No ensaio "Ontology of the Moving Images" (Carroll, 1995), Carroll necessita, para embasar sua ontologia, ultrapassar o estatuto da transparência defendido por Walton. Em Carroll os argumentos são mais diretos e seu estilo irônico. Mas o foco da polêmica em Carroll está também na falta da contextualização da experiência espaço-temporal do corpo que vê, aparecendo enquanto fundamento da diferença entre o "ver ordinariamente" e o "ver através uma fotografia". A partir daí ele avança para estabelecer as decorrências na emergência da intencionalidade própria à representação. Carroll retoma argumento de Currie e diferencia o "ver através" de próteses oculares e espelhos, do "ver fotografias". A diferença está na relação da presença de quem vê com o mundo visto:

se eu olho através de binóculos ("opera glasses") uma bailarina ou seu acompanhante, a disposição visual do que enxergo, mesmo ampliada, continua, sem dúvida, em conexão com meu corpo, no sentido que eu saberia como chegar ao lugar em questão, se quisesse. Posso orientar meu corpo espacialmente para a bailarina e seu acompanhante (Carroll, 1995, p. 71).

Uma coisa, portanto, seria ver o mundo através de telescópios, microscópios, periscópios, espelhos; outra, diferente, seria ver o mundo através de fotografias, na medida em que, neste último caso, ao contrário do que acredita Scruton (1981), buscando absolutizar a dimensão da intencionalidade (ponto no 
qual Walton também se afasta), está envolvido um ato que podemos chamar de "representacional".

Para entender a negação à fotografia de estatuto representacional é necessário entrar dentro da lógica analítica do conceito de "intenção". Tanto para Carroll, como para Walton, pinturas e fotografias são representações do mundo, na medida da intencionalidade, ainda que pressuposta (Carroll, 2004). Walton afirma a singularidade absoluta da representação fotográfica, mas não precisa negar seu estatuto representacional mais amplamente. Basta envolver no caminho semelhança com materiais que, assim como espelhos e próteses oculares, permitem que "vejamos através". 0 ponto, para Walton, está em definir quais singularidades da fotografia se adequam num campo tecnológico diferenciado, inerente às imagens-câmeras, determinadas na medida da mediação necessária que funda o maquinismo câmera. Carroll, no entanto, acredita que esta singularidade representacional que não se sustenta.

0 argumento de Walton é de que realmente estamos vendo os objetos e seres que enxergamos através do dispositivo fotográfico. Não é apenas força de expressão. Seu ponto é que os vemos, sim, do mesmo modo que vemos objetos e seres através de dispositivos oculares ou especulares. Se, através de um dispositivo especular, dizemos que vemos a rosa que está do outro lado da quina da parede do quarto; se, através de um periscópio, dizemos, olhando debaixo da água, que vemos o homem que está na praia; podemos também, através de uma câmera de vigilância, dizer que vemos o cofre do banco sendo arrombado e, através de uma fotografia, dizer que vemos nosso avô Samuel, há muito falecido, em seu tempo de vida. Walton enfatiza que a mesma noção do "ver" designa os quatros atos descritos acima (ver a rosa pelo espelho, ver o homem na praia pelo periscópio, ver o arrombamento pela câmera de vídeo, ver o avô Samuel pela fotografia), contrariando Carroll, para quem o "ver" atual que envolve a contextualização da informação egocêntrica interagindo com as próteses visuais, distingue-se da 
natureza do ver fotografias (este "ver fotográfico" traria uma espécie de "visão alienada" na representação). Walton foge da discussão afirmando que:

não está em questão a quem pertencem os direitos de propriedade da palavra "ver". O objetivo de minha proposição é revelar (...) o tipo de semelhança que a visão da fotografia de um objeto muitas vezes possui com outras formas de vê-lo, e que não está presente na visão de uma pintura do objeto (Walton, 2004, p. 123).

Afirma, assim, que sua "tese da transparência da fotografia é uma tese sobre a visão direta de objetos, e não sobre ver que algo é aquilo mesmo" (Walton, 2004, p. 122). Esta “tese sobre a visão direta de objetos" pela (através) fotografia é sua resposta aos argumentos de ausência de "informação egocêntrica" que restringiriam o "ver através" ao que é "aquilo mesmo" no mundo, situado no contexto sensório-motor simultâneo da presença do espectador. A "visão direta", na qual se funda o "ver através" da fotografia, segundo Walton, seria apenas uma forma mais modesta (mas sempre ontológica em seu abrigo no ser que a atravessa), de ver, ou experimentar, o mundo, agora diretamente por um maquinismo. "Ver através" significa aqui um modo de compartilhar um desvelamento mais amplo, ainda que sua experiência continue limitada, "como" querendo escapar, à temporalidade do ver que carrega consigo, adiante, a visão.

Walton está, portanto, argumentando o que entende ser a fotografia, forma de expressão representacional muitas vezes artística, e sempre marcada, nos termos de nosso autor, pelo corte da representação. Mas não está preocupado com a unicidade da identidade cognitiva do objeto no existir dentro do campo atual, portanto egocêntrico, daquele que vê: "ao ver a fotografia de um cravo, vejo o cravo; não importa se o que vejo mantém comigo esta ou aquela relação espacial" (Walton, 2004, p. 122). Desfeita assim a armadilha da extensão como diferencial para impedir a constituição do ver diretamente em espelhos e fotografias, Walton pode afirmar que a fotografia:

Dossiê Crise, Feminismo e Comunicação - https://revistaecopos.eco.ufrj.br/ 
é também um auxiliar para a visão e um auxiliar particularmente versátil. Com a assistência da câmera, nós podemos ver não só atrás de esquinas, mas também no passado. Nós vemos ancestrais há muito mortos se olhamos para fotos poeirentas deles. (...) Fotografias são transparentes. Nós vemos o mundo através delas (Walton, 1984, p. 251, grifo original).

Ao absorver o "ver através" na dimensão temporal, adentrando as fronteiras do campo transcendental da subjetividade, vamos ao encontro da metafísica e da filosofia de corte existencial, certamente uma área na qual Walton não se sente à vontade, nem deseja fazer ponte para desembocar sua análise. Mas a consequência seria correta, se quiséssemos levar o raciocínio, e a intuição do autor, até o final radical da linha para qual aponta. 0 campo conceitual da filosofia da linguagem é, em grande parte, construído para permitir que a reflexão trabalhe em proximidade com o senso comum cognitivo e os poderes sintáticos da lógica que emergem na semântica da linguagem ordinária - e parar por aí. Aqui, no entanto, fica um ponto cego. Ver fotografias embute a relação com um estar-fora do mundo, por mim. Algo que vem de lá para cá, mas a mim, enquanto "co-existir-aqui", pertence - inclusive vergando, por este mim, uma dimensão além da representação, pois incide no tempo e no fluxo da duração, numa espécie de "analítica existencial do ser-aí". É aquilo que vemos no mundo e do mundo pelo "através", que emana como aura (fotográfica) e nesta auréola vem bater no que já está, por nós, em nós. É de lá para cá que este caminho é percorrido, mas só chegamos a "se" tocar neste ponto negando o próprio caminho - pois ele só existe se já está lá traçado. E o ponto em que ele encontra, o ponto em que ele brilha, é exatamente em seu rebater-se, como intui o belo conceito de "punctum". É o ponto agudo que me atinge, quando fundo minhas sensações na dimensão da intensidade presente, que então vem absoluta como alteridade exatamente por conseguir estar-aqui (pelo "através") junto a mim, no estar: seja olhando através um crime, ou através num rosto conhecido na areia da praia das últimas férias estivais, ou vendo meu falecido avô Samuel:

Dossiê Crise, Feminismo e Comunicação - https://revistaecopos.eco.ufrj.br/ 
Óculos, espelhos e telescópios não fornecem representações imagéticas. Pensar a câmera como outra ferramenta da visão seria esvaziar seu papel de produzir representações imagéticas. Fotografias certamente são imagens, mas não imagens comuns. São imagens através das quais nós vemos o mundo (Walton, 1984, p. 254).

Restaria para Walton responder, e esta é a questão verdadeiramente essencial, como é que é que elas, fotografias, sabem poder assim nos encontrar.

\section{Referências bibliográficas}

AGAMBEN, Giorgio. 0 que é um dispositivo?. Revista Outra Travessia, n. 5, p. 9-16, 2005.

BARTHES, Roland. A Camâra Clara: Nota Sobre a Fotografia. Rio de Janeiro, RJ: Nova Fronteira, 1984.

CARROLL, Noël. "Towards an Ontology of the Moving Image". IN: FREELAND, Cynthia A.; WARTENBERG, Thomas E. (eds.). Philosophy and Film. London, UK: Routledge, 1995. p. 68-85.

"Ficção, não-ficção e o cinema da asserção pressuposta: Uma análise conceitual". IN: RAMOS, Fernão P. Teoria Contemporânea do Cinema: Documentário e Narratividade Ficcional. vol. II. São Paulo SP: Ed. Senac, 2004. p. 69-104.

COMOLLI, Jean-Louis. Caméra, Perspective, Profondeur de Champ. Cahiers du Cinéma, no 229, no 230, no 231, no 233, no 234-235, no 241, 1971-1972.

CURRIE, Gregory. Image and Mind: Film, philosophy and cognitive science. Cambridge, UK: Cambridge University Press, 1995.

DERRIDA, Jacques. A Voz e o Fenômeno. São Paulo, SP: Zahar, 1994.

DUBOIS, Philippe. O Ato Fotográfico. Campinas, SP: Papirus, 1993.

Dossiê Crise, Feminismo e Comunicação - https://revistaecopos.eco.ufrj.br/

ISSN 2175-8689 - v. 23, n. 3, 2020

DOI: 10.29146/eco-pos.v23i3.27615 
FLUSSER, Vilém. Filosofia da Caixa Preta: Ensaios para uma futura filosofia da fotografia. São Paulo, SP: Annablume, 2013.

FOUCAULT, Michel. As Palavras e as Coisas: Uma arqueologia das ciências humanas. São Paulo, SP: Martins Fontes, 2000.

MACHADO, Arlindo. A Ilusão Especular: Uma teoria da fotografia. São Paulo, SP: Brasiliense, 1984.

OUDART, Jean-Pierre. La Suture. Cahiers du Cinéma, no 211/12, abril e maio, 1969.

SCRUTON, Roger. Photography and Representation. Critical Inquiry, v. 7, p. 577-603, 1981.

SONTAG, Susan. Sobre Fotografia. São Paulo, SP: Companhia das Letras, 2004.

WALTON, Kendall. Transparent Pictures: On the nature of photographic realism. Critical Inquiry, v. 11, p. 246-277, dez. 1984.

Mimesis as Make Believe: On the fondations of the representational arts. Cambridge, UK: Harvard University Press, 1990.

"Sobre Imagens e Fotografias: Resposta a algumas objeções". IN: Ramos, Fernão P. Teoria Contemporânea do Cinema: Documentário e Narratividade Ficcional. vol. II. São Paulo, SP: Ed. Senac, 2004. p 105-127. 